\section{P-10 AN ARTS-BASED EVALUATION OF THE BUTTERFLY SERVICE AT THE PRINCE \& PRINCESS OF WALES HOSPICE}

Carol Graham, Mary Cameron, Niki Ferguson. Prince and Princess of Wales Hospice, Glasgow, UK

\subsection{6/bmjspcare-2016-001245.34}

The Butterfly Service supports children and young people (C/YP) up to 18 who face or have experienced bereavement due to a life-limiting illness. It acknowledges the need to identify and support each individual's grief primarily through group work and individual counselling/therapy. The benefit of using an arts-based qualitative process to identify personal needs and evaluate individual experiences was explored.

An art template was created, using the symbols of the heart (representing love and emotions) and the butterfly (service symbol). Two hearts made the wings of the 'heart butterfly, one to be completed about the C/YP special person and the other about the $\mathrm{C} / \mathrm{YP}$ time at the Butterfly Service.

As part of the Butterfly Service's fifth birthday celebrations all of the C/YP who used the service had the opportunity to complete a 'Butterfly Heart' at an art workshop. They were interviewed on camera talking about their completed 'Heart Butterfly', if willing. A short film was created and shown at the birthday celebration event attended by many of the C/YP and families who were supported by the service over the last five years. A display of the original 'Heart Butterfly' artwork was shown at this event and a photographic record of each 'Heart Butterfly was created.

The idea behind the 'Heart Butterfly' is that each C/YP can express and record their feelings about their special person, their experience of the Butterfly Service and the difference it made in their grief journey.

This art evaluation tool

- provided a developmentally accessible way for $\mathrm{C} / \mathrm{YP}$ to tell their stories

- facilitated expression of thoughts and feelings that may be difficult to put into words

- acknowledged their grief and encouraged communication with their family

- is an effective method of assessing the needs of C/YP and gaining feedback on their experience of bereavement.

\section{P-11 EVALUATION OF ISLINGTON BEREAVEMENT SERVICE}

${ }^{1,2}$ Harriet Duthie. 'St Joseph's Hospice, London, UK; ${ }^{2}$ Goldsmiths University, London

\subsection{6/bmjspcare-2016-001245.35}

Background Islington Bereavement Service started providing emotional, social and practical support to bereaved individuals living in Islington in July 2015. Based on the Compassionate Communities approach, the service is designed to empower community members to address their bereavement needs. In doing so, new peer support networks are formed which increases resilience to bereavement within the community.

Aim A service evaluation is being performed on the bereavement service. The main aim of the evaluation is to explore how the service impacts community members and volunteers.

Method Islington Bereavement Service trains bereavement support volunteers to deliver peer-support sessions to community members. In order to assess the impact of the peer-support sessions on community members' wellbeing, attitude to grief and loneliness; questionnaires are being administered to community members before and after receiving peer-support sessions. The questionnaire consists of: the Warwick-Edinburgh Mental Wellbeing Scale, the Adult Attitude to Grief Scale, the UCLA Threeitem Loneliness Scale and cost-effectiveness questions. Community members' satisfaction with the service will also be assessed. The projected sample size is 10 to 15 community members.

Two focus groups are being held with four to six volunteers in each group. The focus groups will explore volunteers' experience of volunteering within the service, their motivation to volunteer and what they have gained from volunteering.

Time frame The evaluation will be completed on 31 August 2016.

Results Wilcoxon signed-rank test will be used to detect significant changes in community member outcomes from before to after receiving support. Recorded data from the focus groups will be transcribed and undergo inductive thematic analysis to detect emerging themes.

Conclusion Implications of predicted results may include: improvement in the quality of support provided, evidence for future funding, evidence for peer-to-peer bereavement support in the community and evidence of the benefits of volunteering.

\section{P-12 MORE THAN EXPRESSIONS OF CONCERN: MEASURING THE IMPACT OF VOLUNTEER BEREAVEMENT SUPPORT}

${ }^{1,2}$ Ros Scott, ${ }^{2}$ Sarah Dundas, ${ }^{2}$ Stewart Wilson. ${ }^{1}$ University of Dundee, UK; ${ }^{2}$ Cruse Bereavement Care Scotland, Perth, UK

10.1136/bmjspcare-2016-001245.36

Introduction The wellbeing of the bereaved people supported by Cruse Bereavement Care Scotland (CBCS) is central to all aspects of our work. It was important to find an evidence-based evaluation tool that could provide an indication of the outcomes for clients of our volunteer face-to-face counselling support. The Warwick-Edinburgh Mental Wellbeing Score (WEMWBS) was chosen and initially piloted with clients in the West of Scotland.

Approach The questionnaire consists of a positively worded 14item scale with five response categories. CBCS volunteers use this with clients at the beginning of the initial session and again during the last session. It is quick and easy for clients to complete and volunteers can provide help to do this if required.

The pilot data gave valuable information about progress made following the support given. Feedback from volunteers and clients was also overwhelmingly positive and the evaluation tool was subsequently rolled out across the organisation.

Findings Of the initial 83 clients evaluated $86 \%$ showed an improvement in wellbeing at the end of the face-to-face sessions. WEMWBS scores are grouped into three wellbeing categories Low, Moderate and High. There was significant change in the different wellbeing categories after intervention with the proportion of clients in the low wellbeing category reducing from $84 \%$ to $30 \%$, the proportion of clients in the moderate wellbeing category increasing from $16 \%$ to $55 \%$ and the proportion of clients in the high wellbeing group from $0 \%$ to $14 \%$.

Conclusion The introduction of WEMWBS has provided an evidence-based tool to measure the effect of our work on the mental wellbeing of clients. The overall findings suggest that CBCS volunteers have a positive impact in improving the wellbeing of the significant majority of clients. 
Warwick-Edinburgh Mental Well-being Scale (WEMWBS)(C) NHS Health Scotland, University of Warwick and University of Edinburgh, 2006, all rights reserved.

\section{P-13 THE PURPLE GROUP - DEVELOPMENT OF A PARENT- LED BEREAVEMENT GROUP - THE JESSIE MAY EXPERIENCE}

\footnotetext{
1,2 Helen Williams, 1,2Liz Lewington, ' Jullie Kembrey. ${ }^{1}$ The Jessie May Trust, Bristol, UK; ${ }^{2}$ University Hospitals Bristol NHS Foundation Trust
}

10.1136/bmjspcare-2016-001245.37

Jessie May is a children's hospice at home charity which was founded in 1994 by the parents of Jessica May following her death aged $4 \frac{1}{2}$ months. Whilst working with the families, Jessie May nurses recognised a need for bereavement support and began to offer parents telephone calls, support visits and send cards to acknowledge the children's birthday and death anniversaries.

In 2010, a recently bereaved Parent Representative for the Clinical Governance Group observed that, as parents 'need to grieve for themselves', there was a gap in the Jessie May bereavement service and initiated discussions around the potential for a parents' support group. Following this discussion, the parent representative worked with the bereavement lead to set up the Purple Group and trialled an initial four meetings. The core purpose was to enable bereaved parents to come together within a peer group to discuss the loss of their children and feelings around that loss, gaining support through shared experiences and would describe it as 'therapeutic' rather than a 'therapy group'. No one would be pressured to speak, but parents would have the opportunity to share their stories and experiences.

So far there have been 26 meetings over six years. There is empathy within the group and parents listen to each other, giving respect and encouragement. Each meeting has no agenda or topic so parents can talk about anything they choose, although recurring themes focus around anniversaries, Christmas and expectations from others for parents to 'move on'.

Meetings are arranged a year in advance to enable parents to plan ahead to attend as many meetings as they wish. Jessie May continues to seek informal feedback from parents and by conducting formal questionnaires to ensure they are providing a service that is useful and needed by all of the parents on the Jessie May bereavement caseload.

\section{Carers}

\section{P-14 HCA FOR CARER SUPPORT AT HOME PILOT}

Elizabeth Attwood. St Peter's Hospice, Bristol, UK

\subsection{6/bmjspcare-2016-001245.38}

'It has been wonderful for me as a carer'.

Context CNSs identified carers as the highest priority area for service development.

Importance Carers are expanding and are at higher risk of ill health compared to non-carers. Poor health can have a detrimental effect on the health and well-being of the person for whom they are caring (Carers UK, 2014).
Aim To provide a programme of support at home to enable carers as caregivers and to allow access to personal support for themselves.

Intervention A programme of visits by a health care assistant to patients and carers on CNS caseload. 43 carers received an average of five visits lasting three hours, totalling 210 visits and 562 hours July 2015 and March 2016.

Approaches included:

- Carer Support Needs Assessment (Ewing and Grande, 2013)

- Respite care

- Emotional support

- 'Gentle Touch'

- Information giving

- Role modelling

Evaluation 10/43 carers returned the questionnaire (ONS, 2013). All the carers responded positively that the service has made a difference to them as carers.

$8 / 10$ gained a lot of benefit and the remainder gained some benefit.

A planned programme of visits and continuity of care led to trust in the health care assistant which enabled the carer to benefit from the service.

\begin{tabular}{ll}
\hline & Impact on care \\
\hline Trust enabled respite & 'I could leave the house without worrying' \\
'my husband was in good hands' & 'anxieties were dealt with' \\
Caring approach facilitated emotional & 'helped put things into perspective' \\
support & 'time to do essential things, that was important \\
Planned respite allowed personal & to us'; \\
support & 'a break from a stressful period'; \\
& 'I could make plans around visits'. \\
& 'dealt with queries'; \\
Practical advice enabled ability to care & 'guided my care of my husband' \\
Good company reduced loneliness & 'someone to talk to and laugh with' \\
\hline
\end{tabular}

All carers felt that the negotiated day, time and duration of visits were convenient. Two would have liked more visits.

Future practice The importance of planning visits and continuity of care for carers to feel prepared to care and supported will be taken forward in a new respite service.

\section{P-15 SHARE AND CARE - SUPPORTING CARERS TO CARE FOR PEOPLE WITH LIFE-LIMITING ILLNESSES}

Catherine Thompson, Jackie Holmes, Stephen Oxberry, Michael Crowther. Kirkwood Hospice, Huddersfield, UK

\subsection{6/bmjspcare-2016-001245.39}

Share and Care is an innovative project developed within the hospice setting run in collaboration with a carers charity and the local authority to improve support, knowledge and education for carers of individuals with life- limiting illnesses. The course was designed to deliver specialist support to carers, an area for development identified within the hospice User Forum.

Share and Care provides sessions on a variety of topics including:

- Helping people to move safely

- Protecting vulnerable skin and preventing pressure sores 